\title{
CORPO NA ARTE, BODY ART, BODY MODIFICATION: FRONTEIRAS
}

Priscilla Ramos da Silva ${ }^{1}$

\section{Resumo}

Tão freqüentemente associado à produção artística atual, o termo corpo na arte é, para muitos, uma incógnita. Afinal, do que se trata falar, simultaneamente em arte e corpo? A junção das duas palavras parece, à primeira vista, mais confundir do que esclarecer. Com freqüência, a arte do corpo dos anos 1990/2000 é confundida duas outras manifestações em que o corpo é o suporte da criação: a body art dos anos 1960/70 e o a body modification, fenômeno que compreende a realização de piercings, tatuagens, escarificações e outras intervenções corporais. No que se refere à arte contemporânea, um estudo aprofundado sobre a questão do corpo deve se deter, de início, sobre duas questões metodológicas fundamentais: a primeira é a definição o do próprio termo corpo na arte. A segunda, a delimitação das fronteiras entre os três campos de ação distintos: a arte do corpo atual, body art e a body modification. Estas serão as questões discutidas nesta comunicação.

Palavras-chave: body art, body modification, corpo na arte contemporânea.

\begin{abstract}
So frequently associated with the current artistic production, the term body in art is, for many, uncertain. What does it mean, after all, talking simultaneously about art and the body? The junction of the two words seems, at first, more confusing than clarifying. Quite frequently, the art of the body of the 1990's and 2000's is confused with two other practices in which the body is the means of expression: the 1960's and 70's body art and body modification, a phenomenon which comprehends the making of piercing, tattoo, scarification and other body interventions. When it comes to contemporary art, a deepened inquiry into the body issue must be concentrated, from the beginning, on two fundamental methodological questions: the first being the definition of the own term body in art. The second, the delimitation of the boundaries between the three distinct fields of action: the current art of the body, body art and body modification.
\end{abstract}

Keywords: body art, body modification, body in contemporary art.

\section{Introdução}

Tão freqüentemente associado à produção artística atual, o termo corpo na arte é, para muitos, uma incógnita. Afinal, do que se trata falar, simultaneamente em arte e corpo? A junção das duas palavras parece, à primeira vista, mais confundir do que esclarecer. Com freqüência, a arte do corpo dos anos 1990/2000 é confundida duas outras manifestações em que o corpo é o suporte da criação: a body art dos anos 1960/70 e o a body modification, fenômeno que compreende a realização de piercings, tatuagens, escarificações e outras intervenções corporais. No que se refere à arte contemporânea, um estudo aprofundado sobre a questão do corpo

\footnotetext{
${ }^{1}$ UNICAMP - Mestrado em Artes - Linha de pesquisa: Arte, Cultura e Sociedade.
} 
deve se deter sobre duas questões metodológicas fundamentais: a primeira é a definição o do próprio termo corpo na arte. A segunda, a delimitação das fronteiras entre os três campos de ação distintos: a arte do corpo atual, body art e a body modification.

\section{Body Art}

No final da década de 1950, a arte permite o surgimento de uma relação totalmente nova com o corpo. Para além de pintado ou desenhado, o corpo passa a ser apresentado. Surge a body art, decretando o corpo o suporte da obra da arte.

É justamente aqui que nosso percurso tem início. Não é possível compreender o que atualmente chamamos de arte do corpo (ou corpo na arte) sem nos reportarmos ao rótulo cunhado nos anos 60. A body art põe o corpo em tão em evidência, e o submete a experimentações tão variadas, que sua influência estende-se aos dias de hoje. Se na arte atual as possibilidades de investigação do corpo parecem ilimitadas - pode-se escolher entre representar, apresentar, ou ainda apenas evocar o corpo - isto ocorre graças ao legado dos artistas pioneiros que, há décadas, fizeram de seus corpos meios privilegiados de expressão.

Compreendendo uma variada gama de procedimentos, a body art é um conceito amplo. Nos anos 70 e 60, práticas corporais as mais diversas foram apresentadas como arte: há quem tenha se despido, se lambuzado de tinta e se deixado manipular de maneira irrestrita pelo público. Há quem tenha comido vidro, bebido sangue, levado tiros e até se masturbado no museu. Correm lendas (e elas são apenas lendas) de quem tenha se castrado ou mesmo se suicidado em nome da arte.

Certamente, proposições radicais como estas não foram recebidas com indiferença na época em que foram realizadas. Ainda hoje, a body art impressiona pela intensidade de suas experiências, e a audácia - ou a loucura - de seus artistas. Suscitando um misto de atração e repulsa, e operando na contramão do ideal clássico de arte, a body art convida à reflexão.

Dentre todas as experimentações às quais o corpo foi submetido, as mais polêmicas foram, sem dúvida, aquelas em que a violência ou a auto-mutilação foram empregadas. Citemos, como exemplos, as performances da artista Gina Pane. No início dos anos 70, Pane havia engolido carne moída estragada, se cortado com lâminas, mastigado vidro, subido uma escada cravejada de pontas cortantes e realizado uma série de outras ações semelhantes.

Há que se perguntar, naturalmente, a quê poderíamos creditar tamanha hostilidade ao corpo na body art. Ferir para libertar - eis um dos principais intuitos do ataque à pele e à carne na arte do período. Crescia, frente a um ambiente repressivo, a ânsia pela construção de um novo homem e uma nova sociedade; uma sociedade, segundo o crítico François Pluchart, "enfim livre e harmoniosa, livre de falsa ética, ditadores de qualquer tipo, ideologias repressivas e censores". Neste contexto, o corpo se apresentava como um instrumento de ação social e uma poderosa arma, através da qual era possível, ainda nas palavras de Pluchart, "denunciar determinismos, tabus, obstáculos à liberdade e à expressão do indivíduo"2.

$\mathrm{Na}$ body art, a investida violenta contra o corpo visava chocar o espectador, retirando-o de um estado de indiferença e passividade. A questão era despertar a consciência do indivíduo, tanto frente à arte, quanto à vida. Neste processo, o artista se posicionava muitas vezes como um guia ou messias, cuja atuação traria a salvação do homem.

Devemos assinalar, naturalmente, que nem todos os artistas da body art se alinharam a este ideal libertário. Vale mencionar aqui o performer australiano Stelarc que, desde os anos 70, 
procura ampliar o corpo através de próteses e extensões dos mais variados tipos. Os trabalhos mais conhecidos de Stelarc são as suspensões - performances em que o artista é pendurado através de ganchos que perfuram sua pele. Quando falamos em suspensões, devemos lembrar que esta prática foi tanto explorada por artistas integrados ao sistema "formal" da arte quanto por adeptos da body modification - indivíduos que realizam intervenções sobre seus corpos.

\section{Body modification}

Segundo Beatriz Pires, autora do livro O corpo como suporte da arte, o conceito body modification designa as modificações corporais executadas das mais diversas formas. Entre seus procedimentos estão "a mudança das cores da epiderme e a feitura de incisões, queimaduras, perfurações, mutilações e implantes de diferentes tipos, com a finalidade de modificar os contornos e acrescentar elementos à silhueta (...)"3. Em seu estudo, a autora trata não daqueles que modificam seus corpos em função da moda, mas de indivíduos para a quais a body modification possui outros significados - sejam eles psicológicos, filosóficos ou mesmo religiosos. Entre estas pessoas, estão os modern primitives - grupo de adeptos de modificações corporais para os quais a manipulação do corpo possui um caráter místico e transcendental. Fakir Musafar, criador do termo modern primitives, lista algumas das práticas da body modification, às quais ele ele chama de "jogos"(cito aqui três dos sete itens mencionados por Fakir):

5) Jogos com fogo: queimar.

Utilizam bronzeamento exagerado, corrente elétrica aplicada de forma contínua ou através de choques, vapor e calor, marcas feitas a ferro ou por queimaduras, etc.

6) Jogos de penetrações: invadir.

Compreendem flagelações, perfurações, tatuagens, o ato de picar-se, espetar-se, deitar sobre cama de pregos ou espadas, injetar-se agentes químicos, etc.

7) Jogos de suspensão: pendurar.

A suspensão, por meio de ganchos de açougueiro, pode ser feita em cruz, pelos pulsos, coxas, peito, tornozelos, associada a constrições ou a múltiplos furos pelo corpo, etc. ${ }^{4}$

Nota-se como muitos dos jogos mencionados por Musafar já foram explorados por artistas da body art, entretanto, cabe estabelecer as semelhanças e diferenças entre as modificações corporais e a arte do corpo. Até que ponto a body modification pode ser entendida como arte? Ainda que em geral se defina tanto a body art quanto a body modification enquanto práticas nas quais o corpo é o suporte da arte, há que se esclarecer o que se entende, em cada um dos casos, pela palavra "arte".

Quando se fala em body modification, o termo arte não se refere, necessariamente, à arte dos museus e galerias. A intervenção sobre o corpo é chamada de "arte" não porque quem a realiza é um artista plástico, mas porque se considera que, ao alterar seu o corpo, o indivíduo o faz de maneira criativa, de modo a obter determinados resultados estéticos.

Já quando nos referimos à body art (anos 60/70) ou ao corpo na arte (anos 90/2000) tratamos justamente de uma arte inserida em determinado sistema - isto é, arte feita por indivíduos que se declaram artistas, cuja produção é exibida em museus e/ou galerias. Embora a body modification não se insira, na maioria das vezes, no espaço institucionalizado da arte, ela se aproxima em muitos aspectos da body art. Basicamente, a body modification e a body art possuem as seguintes características em comum: as intervenções sobre o corpo; o caráter positivo atribuído à agressão corporal; a presença do ritual; e a identificação do artista/indivíduo com o xamã ou o mártir. 
O que mais une as duas práticas que viemos discutindo é, certamente, a intervenção sobre o corpo. Em linhas gerais, podemos dividir as intervenções corporais em basicamente três niveis. A maneira mais direta ou radical pela qual o corpo pode ser trabalhado é, a meu ver, aquela em que há ruptura ou alteração da estrutura da pele. Aqui se encaixam a maioria dos procedimentos da body modification, e alguns dos procedimentos da body art. A pele é perfurada, costurada, submetida a implantes, tatuagens e queimaduras. Busca-se macular a pele (perfurações, costuras, suspensões), ou marcá-la e alterá-la definitivamente (tatuagens, escarificações, cirurgias plásticas, implantes). Os adeptos da body modification parecem buscar alterações definitivas mais freqüentemente do que os artistas da body art. Como observa Beatriz Pires,

\begin{abstract}
a body modification cria uma relação do artista com o corpo totalmente diferente das estabelecidas pela body art e pela performance. Nela, a relação corpo-objeto é independente da relação tempo-espaço (...). Não há distinção entre o artista e a obra, entre o sujeito criador e o objeto criado. O sujeito é o objeto e não deixará de ser, independentemente do tempo e do espaço em que se encontre. $\mathrm{O}$ evento artístico não se reduz ao tempo da exposição ou da apresentação. O tempo de exposição é o tempo de vida do indivíduo, e o espaço destinado a ela é composto por todos os ambientes por onde ele circula. Não vigora aqui a premissa do pensamento racional, de discurso conceitual. A obra é determinada pelo inconsciente, pelo afeto; é designada como algo fundamental para a formação da identidade do sujeito. ${ }^{5}$
\end{abstract}

Um outro nível segundo o qual o corpo pode ser trabalhado é aquele em que ele transforma-se em tela ou pincel. Aqui, a pele não é desafiada ou alterada de modo permanente; não há cortes nem danos ao tecido. A pele apenas muda temporariamente impregnando-se dos mais diversos materiais (tinta, cosméticos, barro, lama, sangue animal e outros). O corpo como ferramenta ou suporte da pintura foi explorado em diversas ocasiões pelos artistas da body art, especialmente em performances. Já a body modification não parece se identificar com esta relação efêmera entre corpo e pintura.

Muito menos a body modification se aproxima da arte em que o corpo é substituído por algo que remeta a ele - e é aqui que devemos introduzir a discussão sobre corpo na arte dos anos 90/2000. Como vimos, os adeptos das modificações corporais não desejam trabalhar sobre quaisquer outros suportes que não seus próprios corpos. Já grande parte dos artistas trabalhando $o$ corpo na arte atualmente prefere referir-se ao corpo a atuar diretamente sobre ele.

\title{
O corpo na arte dos anos $90 / 2000$
}

Reina, atualmente, um conceito amplo sobre o corpo na arte - tão amplo que sua própria validade tem sido questionada. Num artigo sobre a exposição $O$ corpo na arte contemporânea brasileira, realizada em 2005 no Instituto Itaú Cultural, em São Paulo, o crítico Teixeira Coelho comentava:

A questão mais específica a esta mostra desdobra-se em duas: 1) O que é corpo, afinal? A maleta 007 com pregos no interior; um vestido; arte do corpo, arte com o corpo? Se forem, tudo é corpo, então nada é; 2) O que é arte para esta exposição?, pergunta motivada pelo vídeo com Lygia Clark e os gadgets sensoriais para passar no corpo de seus pacientes e com isso "tratá-los": arte é terapia, aqueles gadgets são arte? Se sim, a psicanálise e o rolinho japonês que passo no pé também. Uma exposição que faz pensar...6 
Uma maleta, um vestido, uma coleção de objetos terapêuticos - como relacionar tais objetos à arte e ao corpo? Eis a pergunta do crítico frente às obras de Carlos Zilio, Nazareth Pacheco e Lygia Clark. Há que se admitir o exagero de Teixeira Coelho ao criticar a presença da "terapia" de Lygia Clark na galeria: o fato de a artista ter se tornado terapeuta não a torna irrelevante para a "arte do museu", nem esgota o interesse em suas investigações sobre o corpo. Já no que se refere à maleta de Carlos Zilio, o crítico coloca uma questão pertinente: onde, exatamente, está o corpo nesta obra? O desconcerto do crítico frente à total ausência do corpo justifica-se, em parte, pelo fato de muitas das "obras sobre o corpo" atuais não mais representarem o corpo. De fato, o corpo representado (em desenho, pintura ou escultura) permanece na arte, ao lado do corpo apresentado (como na performance) ou do corpo evocado (através de fotografias, vídeos, moldes, traços, vestígios, objetos, etc.). A vertente da arte contemporânea que se ocupa do corpo evocado é, sem dúvida, a mais intrigante. Na referida obra de Nazareth Pacheco, um corpo aparentemente ausente toma forma dentro de um vestido feito de miçangas e lãminas de barbear: como, diante de um objeto tão sedutor e ameaçador, feito para vestir, não se imaginar o (próprio) corpo? Já na maleta de Calos Zilio, o enigma permanece: nem mesmo um corpo fantasma parece vir à tona quando do encontro com o objeto.

Quando falamos do corpo evocado, estamos estabelecendo uma diferença entre a body art e o corpo na arte atual. Se antes havia uma intensa desmaterialização da obra de arte, hoje o corpo aparece predominantemente em objetos. Porém, acima disto, o que caracteriza o que chamamos de corpo na arte contemporânea é um novo modelo de corporeidade, muito bem definido por Stella Senra:

(...) o corpo que se oferece ao discurso cultural e à experimentação artística (...) não é o mesmo que sediou as liberdades nos anos 60-70 - o corpo que foi, ao mesmo tempo, lugar da identidade e de seu questionamento, meio de expressão e inscrição no espaçotempo. Com o recente desenvolvimento da genética e da informática, os anos 80-90 assistem a um deslocamento do modelo de corporeidade: a engenharia genética, a clonagem, a robótica, as próteses, a descoberta do vírus da AIDS, mas também a reprodução assistida e a reprodução sem sexo passam a colocar em questão a integridade corporal, a embaralhar os limites biológicos e a distinção entre as espécies, entre o humano e as máquinas(...) também no plano social o corpo passa a ser visto sob uma nova perspectiva: novos comportamentos valorizam o "desempenho" físico, fazendo do corpo algo a ser "construído" por meio de técnicas de modelagem. ${ }^{7}$

Outro fator importante no que se refere à arte do corpo atual é o esvaziamento da questão política que caracterizara a body art. Ao longo do tempo, os aspectos outrora dramáticos da liberação do corpo foram se transformando. Pode-se afirmar que a arte do corpo, atualmente, ocupa-se mais do indivíduo que da coletividade. Reina uma arte instrospectiva com as características de um diário: intimista, confessional, particular. No discurso sobre o corpo, há um deslocamento do social ao privado, ou da política rumo à psicologia (como quer o crítico Hal Foster). O que um dia foi celebração comunitária converte-se em certa solidão, e, findas as utopias, a arte passa a incorporar em seu vocabulário algo da frieza e da incomunicabilidade contemporâneas. 
Procuramos, nesta comunicação, caracterizar a body art, a body modification e a arte do corpo. Conclui-se, pelo texto incompleto aqui apresentado, que a questão é ampla demais para ser resolvida em um espaço limitado. Buscamos, com esta reflexão, apenas lançar ao debate algumas das questões envolvendo o corpo e a arte na contemporaneidade. Estabelecer os limites entre as os três campos de ação aqui mencionados não é uma tarefa simples. Qual seria a essência de cada uma dessas práticas? É difícil dizer - ainda mais quando se tem em conta o quanto a body art, a body modification e a arte do corpo podem, ocasionalmente, se interrelacionar.

2 PLUCHART, François. Risk as the practice of thought (1978). In: WARR, Tracey (ed.), The Artist's Body. Londres: Phaidon, 2000, p.219.

3 PIRES, Beatriz Ferreira. O corpo como suporte da Arte. São Paulo: Ed. SENAC, 2005, p.18

${ }^{4}$ Fakir Musafar, apud PIRES, Beatriz, O corpo como suporte da arte, cit.,p.115-116.

5 PIRES, Beatriz Ferreira. O corpo como suporte da Arte. São Paulo: Ed. SENAC, 2005, p. 138-139.

${ }^{6}$ COELHO, Teixeira. "Assim é se lhe parece". In: Bravo! Online.

http://www.bravoonline.com.br/impressa.php?edit=ap\&numEd=92 acesso em 28/03/2006.

${ }^{7}$ SENRA, Stella. A tela e a pele - cinema, vídeo e computador. In: Metacorpos. São Paulo: Paço das Artes, 2003. 